\title{
Critical Reflections on Human Technology Interaction in the Gerontological Context
}

\author{
Martin Pallauf ${ }^{1 *}$, Ismail Tufan ${ }^{2}$ and Esfandiar Tabari ${ }^{1}$ \\ ${ }^{1}$ Institute for Gerontology and Demographic Development, UMIT - The Health and Life Sciences University, Austria \\ ${ }^{2}$ Department of Gerontology, Akdeniz University Antalya, Turkey
}

*Corresponding author: Martin Pallauf, Senior Scientist, Institute for Gerontology and Demographic Development, UMIT - The Health and Life Sciences University, Eduard Wallnoefer Zentrum 16060 Hall in Tirol, Austria

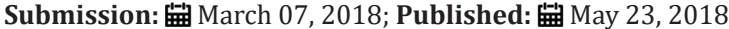

\begin{abstract}
The interaction of elderly people with technology is not a modern-day phenomenon. Man has always been interested in technical devices. In today's age of digitalization, however, this relationship is taking on new significance. From the view point of elderly people, not only digital technical support possibilities need to be considered, but also analog devices as these are often more easily accessible. The present article analyzes the interaction of elderly people and technology in relation to the following categories: communication, mobility, convenience, leisure and play as well as work. For each of these categories, technical aspects are presented, critically analyzed and complemented with philosophical thoughts. Next, a project is presented where these aspects have been implemented in practice. Elderly people were provided with technical support possibilities based on their needs and wishes. Their experiences and the operation of these devices were evaluated for a one-year test period. The synthesis addresses the individualization of technical solutions and the relation to 'man as subject'. It also focuses on aspects like the power of technology or pursues the question whether it makes sense to use it. Finally, it is being discussed, in how far a process of adaptation to technology is sensible and necessary for elderly people and what will be the effect.
\end{abstract}

Keywords: Human technology interaction; Gerontology; Ambient assisted living

\section{Introduction}

Today, elderly people are being confronted with technical solutions which are meant to support them in their everyday lives. If we now take a closer look at the interaction between elderly people and technical solutions, it is necessary to define beforehand what is meant by elderly people as well as by 'technical solutions'.

People who have passed a certain age are often referred to as elderly people. The cutoff age - depending on the point of view - may already be the age of 55, but it can also be the age of 70 [1]. Very often, the legal retirement age of 65 years is used as an indicator. Irrespective of the used cutoff age, all those people have in common that they come from a generation who did not grow up in today's digitalized world. Now, they are confronted with something which they only got to know in the course of their lives; one could call them a "non-technology" generation or digital immigrants [2]. Of course, also elderly people have experience with technology as there have always existed technical devices over the course of human history. Elderly people's experiences, however, are primarily based on analog technical devices and, with that, the subject of technical solutions is raised. When we are dealing with the relationship between man and technology, from the viewpoint of elderly people, it is necessary to deal with all kinds of technical solutions in order to get an overview. Thus, this does not only include ambient assisted living [3] or digitalization, but also technical solutions like a walker which supports elderly people in everyday life. The term 'technology' should not only be considered from the digital perspective, but also from the analog or mechanical perspective.

Here, the reference is to the paradigm of digitalization. We live in the age of digitalization and for a multitude of everyday situations there exist technical solutions; these are digital solutions which provide support via networking. However, it is important to break free from this unilateralist view - especially with regard to the involvement of elderly people - and to include analog technology as well. Indeed, it is this type of technology which - for elderly people - is easier to manage as they are able to understand its functioning, whereas digital solutions are much more complicated to understand.

\section{Technology as Subject and Object}

Besides, for further considerations, it is important to know that technology can act as object or subject. Technology as subject refers 
to what it does to man; in other words, how technology, due to its function, has an influence on man. For this reason, according to Jonas [4], man becomes, object of his own skills. So, the underlying question is, how does technology influence elderly people. Technology as subject, however, refers to issues of functionality. This in turn means how man takes advantage of technology; namely, how the provided functionality can help man. It is a twoway process and therefore needs to be considered under the aspect of how man influences technology. In terms of human-technologyinteraction, it is to say that there is mutual influence, that is, on the one hand, man influences technology, and, on the other hand, technology influences man.

Technology, in this understanding, needs to be seen in a wider context. In order to make the argumentation more understandable and comprehensible, a categorization can be used to observe the various influence and support possibilities of technology. Possible classification systems for categorization are, for example, tAALxonomy [5], but, according to the authors of this article, theyare too differentiated. The categorization or sub categorization of technology can thus be performed using two different perspectives:

A. Focus on technology and distinguish the technical fields based on their function, like, for example, painting technology, construction technology, electrical engineering, etc. or

B. Focus on the benefit for man and the resulting aspects of life like communication, mobility, etc.

The categorization, which has been performed here by the authors, refers to this second perspective. A multitude of technical solutions that promise elderly people support is available on the market and these solutions focus on very different aspects of life. Therefore, the further description will be based on the following categories:
A. Communication
B. Mobility
C. Convenience
D. Leisure and play
E. Work

In the following, these categories will be described and discussed in detail, including essential aspects. The authors do not intend to give a detailed description but rather want to expand on the interesting aspects of each category, from their point of view. Thus, technological progress in the various categories or subcategories can be interpreted in a widening of the range of possibilities. According to Hubig [6], there are three types of possibilities: "real, hypothetical and meta possibilities". Real possibilities have a set framework or definition. Hypothetical possibilities range within a more flexible framework or definition. With meta possibilities nothing is fixed, there is no definition. On the other hand, these technical categories are confronted with the human needs. According to Cassirer [7], the needs grow faster than the possibilities to meet them. Therefore, he distinguishes between true technological progress and capitalist profit maximization which is not a progress as such. Thus, we experience a contradiction in all the technical categories: on the one hand, progress to multiply the range of possibilities leading to more human happiness and satisfaction, and, on the other hand, capitalist profit maximization which prefers real possibilities for its targets.

\section{Category communication}

Communication is an important category when discussing Human-Technology Interaction in elderly people. Based on the above mentioned approach, here, above all, it is of interest to investigate in how far communication through the adoption of technical solutions affects the living environment of elderly people. Some often mentioned challenges of old age are, for example, loneliness and a sense of isolation. During the life course, work is an element of social distinction which ceases to exist in higher age due to the fact that elderly people are no longer working. Therefore, it can be said that elderly people live in another living environment and thus behave and feel differently. Due to a limited social environment and limited mobility it is often hard for them to keep social contacts. One positive note is that technical solutions, like, for example, video telephony, enable elderly people to resume these contacts so that they are able to reconnect with their social environment. Though, this means of communication must not replace personal contacts as this would lead to increased loneliness and isolation. However, this is not favorable for all generations. In younger people, it has the opposite effect, as digital networking is perceived as less burdensome and direct communication is no longer necessary. For elderly people, however, it is kind of a widening of their possibilities which might have a positive effect on their living environment.

Another positive aspect is that by providing technical support, information is more easily accessible and hobbies can be practiced. So, the use of online music offers is a possibility to enjoy personal favorites quickly and straightforwardly. There are, of course, negative aspects as well. So, in this context, commercialization plays a major role. The multitude of possibilities and offers intends to intensify elderly people's shopping activities and to encourage them to buy products. Today, we are living in a multi-option society which does not stop when it comes to technology. Thus, access is easy and there is great temptation. However, it should always be considered if it can bring personal benefit as well, since these extended possibilities, at the same time, restrict people's personal freedom. We might also call it the power of technology which is driven by commercialization.

Technology can also lead to dependence. Dependence always means loss of freedom. Thus, the question arises, how much freedom do elderly people need. In comparison to the younger generation, elderly people put a lot of emphasis on safety and convenience which they expect from technology. Therefore, this loss of freedom should not be considered exclusively as a negative factor, but can be regarded as intended sacrifice. On the other hand, the need for communication increases with higher age, according to 
empirical studies. However, it is questionable and highly individual, in how far technical means of communication in social networks are able to satisfy these needs.

Uncompromised functionality, however, is essential; technology has to work. If this is not the case, the result is negative dependence without any benefit at all. We could even talk about alack of freedom. Up to this point, the aspect of freedom was not a major issue. It must be emphasized, however, that technology cannot always function without complications. There is no universal commitment ensuring continued accurate functioning. Subsequently, this means that elderly people often are not able to solve problems themselves but depend on the help of others. The result is a certain dependence on experts and, in addition, on technology. Therefore, it is vital to teach elderly people technical skills in order to make their use of technology more natural. Initial attempts have already been made by training so-called Senioren-Technik Botschafter' (tech trainers for seniors) or by offering similar support services that should facilitate, in particular, elderly people's access to technology and should pass on information on functionality in a comprehensible way.

Finally, a key aspect is the missing generational connectivity. It occurs due to the fast pace of technical development and will also continue in further generations. At the moment, the older generation is regarded not so technology-adept, provided that technology means digital technology in this context. These people have not grown up in a digitalized world and have been forced to learn how to deal with technology in the course of their lives. So, we could assume that in the future, generations will grow old who have been dealing with technology all their lives and know how to handle it. This, however, is in contrast to the extremely fast pace of technical development which results in the fact that also future older generations - although they have experienced technical socialization- will only with difficulty be able to manage up-to-date technical solutions, as they are usually developed by younger people with this particular generation's understanding For younger people, today's technology is a matter of course, where as for elderly people it is always a great challenge.

However, it is irrefutable that, in the future, the world will be accompanied by technology. In all areas of life there will be networked systems and it will be almost impossible to escape this development. Therefore, senior-oriented offers are required in order to use and to benefit from technology which indeed could be designed specifically for elderly people.

The greatest obstacle to the use of technical solutions are the difficulties of operating them. Especially people who are unexperienced are often overwhelmed by their complexity. A presumably simple means of communication, for example an Email, might appear confusing and complex to elderly people, wherefore they will not use it. A perhaps more simple and intuitive form of communication are social networks. Facebook, the most popular social network, for example, reports the relatively largest increase in users in the age group 55 or older. Here, elderly people seem to do okay and seem to profit from information and contact opportunities. At this point, another essential aspect comes into play: for elderly people, the benefit must be obvious. If they cannot identify the benefit, they quickly lose interest. Though, benefit is often opposed by complicated handling, which can also produce stress in case of failure. Only if this stress is minimal or not existent, elderly people will be willing to accept technology.

This is also related to the different generation-specific approaches to technology. Young people approach unknown technical solutions fearless and mostly unimpressed, whereas elderly people often feel insecure or afraid of doing something wrong. Subsequently, these results in rejection as the effects of technology cannot be anticipated.

If we try to 'see' this topic from a different metaphysical point of view we could talk about alienation. Elderly people create an alienated world, a virtual reality within their own living environment. How are elderly people dealing with this virtual reality? Younger people can find 'permanent salvation' in the virtual world [8]. A feeling of satisfaction sets in at the moment when virtual reality makes is possible. Elderly people, however, seek for long-term solutions, therefore this 'parallel world' is not appealing to them. Virtual realityis not tangible for elderly people. For them, physical presence, which has another meaning and is directly related to the concept of 'life', is in the foreground. In the virtual world this does not work; because the concept of 'life' is a concept of infinity. Our idea of virtual presence always has finite dimensions. Virtual presence cannot replace real presence, it can merely be something additional. But, this addition needs to be understood, on the one hand, and, on the other hand, its added value must become evident as the interest in the virtual reality decreases during the course of life. There is a growing awareness of the finite nature of man. It is what we associate with this finite nature. Virtual presence is intangible and infinite. In older age, people mostly and primarily live in the real world. As they concentrate on their existence in the real world, the virtual world becomes less important to them, they withdraw themselves from virtual reality.

In conclusion, we can say that from the technical viewpoint the assessment is rather positive, whereas from the human viewpoint - and here, in particular, from the viewpoint of elderly people - it is rather negative.

\section{Category mobility}

Also mobility can benefit from technology in many ways. As already shortly explained in the category communication, people's range of mobility decreases in older age. However, various technical solutions can help to moderate this decline. Means of technical support in this context are devices which help to reduce physical limitations, like, for example, a walker. Such simple devices can also be upgraded by installing navigation aids to facilitate people's mobility outside their homes. But also medical devices, like a pacemaker, can contribute to the preservation of people's mobility and activity. 
The positive impacts of this support of mobility are obvious. The preservation of mobility, also in higher age, results in feelings of happiness which have a positive effect on the quality of life. In return, it is also important to have a critical and more differentiated view on this matter. The traditional means of individual mobility is the car. People often use it also in higher age as it provides independence. The trend shows that a lot of technical amenities have been added to modern cars that go beyond the functional aspects of mobility and shall provide more convenience. However, this increases the risk of distraction from traffic as in higher age these features can only be operated with maximum concentration. Autonomous driving, which is currently under development, may be a sensible solution.

It is important to keep in mind that mobility, especially in higher age, plays a major role in enabling people to participate in a social environment and to stay active. Decreasing mobility often has negative effects, as people have to withdraw from roles and obligations. Thus, it is favorable if mobility can be supported and preserved by technical solutions.

Society often associates being old with being disabled or limited mobility. Elderly people need support, they are old and they are not fit. This is in contrast to the concept of 'successful aging'. Successful aging propagates that people in higher age can still be successful or even have to be. But this can also create stress, especially if there are physical limitations or a person's mobility is no longer as it used to be. This may lead to the rejection of technical support possibilities in order to avoid stigmatization since the general rule says: grow old, stay healthy, and remain mobile. But reality looks somewhat different in most cases. Physical limitations and reduced fitness are normal in the process of aging. People want to avoid any peculiarities in daily life - and especially in the public.

Technological support promises a long and healthy life. This image is deeply rooted in technological societies and will be transported farther. But this image is quite contradictory from the gerontological point of view. An elderly person with a walker does not fit the propagated image of an old healthy person. This is perceived as stigmatization and people want to escape from it. Therefore, they prefer to go by car in order to lose their stigma and not to stand out in today's youthful society. This can eventually result in unwanted potential dangers and particular attention should be paid to safety aspects.

\section{Category convenience}

Convenience plays an increasingly important role in today's society and can be achieved through or facilitated by technology. So, we could talk about convenience in the digital world or due to the digital world. This primarily refers to technical devices or operating aids which provide or promise all-day convenience and can be operated by everybody. This may be, for example, a tablet which controls the home automation. The user interface is a touchdisplay that offers various individual, configurable functions. Elderly people often distance themselves from exactly this type of device. They are not used to operating the device and the range of possibilities discourages them rather than makes them see the benefits of learning how to handle such a device. In that respect, elderly people are rather distrustful and not very adventurous. They can, without difficulty, use familiar operating aids - like, for example, the TV remote control - over a long period of time, but they have difficulties to accept the digitalization of the tools within their homes and surroundings.

It is therefore necessary to convey the positive effects of technology and to outline the benefits, in particular for elderly people, namely that technology contributes to an increase in convenience and can provide a comfortable living situation. But this is only possible if user-friendliness is guaranteed by ease of use and a clear user interface.

Technology has already made a highly positive contribution in this area. But technology also sets the pace; the user must adapt to technology. Generational comparison shows that elderly people are rather unwilling to buy new technical devices. They wish and clearly prefer to repair things. Just because something causes problems does not mean that you have to replace it. The situation in the younger generation is different. In most cases, technical devices will be replaced by new up-to-date ones if they cause problems. Repairs are an exception as they are often more expensive and the replacement with newer up-to-date technology seems more useful. Due to their different approach, elderly people lack flexibility in this matter. Thus, they are severely reluctant to buy new technical devices. In general, their interest in new devices is rather reserved as long as the old ones still work. The throw-away-mentality, which is especially widespread among the younger generation, is not common among elderly people due to their experiences and availability in earlier times. Therefore, access to new developments is harder for elderly people because devices are used over a longer period of time.

\section{Category leisure and play}

The category leisure and play mainly includes conventional devices like TV and radio. They are not part of the category communication as, in contrast to communication devices, only passive reception is required here. This means once they are turned on, the recipient only has to listen, no active effort on the part of the recipient is necessary. These two devices, in particular, are used by many elderly people. This could be explained by the fact that those devices are already familiar to this generation and therefore access is simple and clear. However, this category also includes possibilities for entertainment and games. Elderly people want to entertain themselves in their leisure time, which is not always possible by means of interpersonal contact. Therefore, they also play online games.

We can see that there are major discrepancies. Younger people learn in a playful way, this also applies for technology. Elderly people are more rational. For example, elderly people need a user's manual for technical devices as they want to be sure that they do everything right. This instruction is analog and supplemented with individual instructions so as to have a clear and straight forward 
approach. Playful handling and flexibility is not very common in higher age. The older people get, the more they are bound to reality and their living environment. Games, however, always have a virtual character and elderly people are alienated from such items. They also have an infinite character as the end is open. This introduces an aspect of chaos, of infinity. Elderly people, however, are so familiar with mortality and their own body that this virtual reality is not relevant for them. The digital homo ludens is primarily met among younger people. Elderly people prefer games with a clear ending.

\section{Category work}

Digitalization and technology are already widespread in the workplace environment and will be pushed and intensified in the future. Work is defined as employment with financial reward. However, in the framework of this article, elderly people are defined as people who have already retired. Thus, this category seems to be rather irrelevant. But it is still important, as elderly people throughout their life - and in particular during their active working life - experience technological progress which affects them personally and which they have to follow in order to stay up-todate.

On the occasion of their retirement, elderly people in a way lose one of their characteristics, namely their job. During their working life, people spend the major part of their time in their job, creating an identity. For people who identify with their work, the loss of their job is also a loss of their identity. The digitalized world also influences the working world to a large extent. In many fields, work becomes more technological, faster and more flexible, and sometimes it even replaces leisure time. Or in other words: work becomes leisure. Due to the digitalization there is no more difference between work and leisure time, if, for example, E-Mails are processed outside the regular working hours. Of course, this does not apply to all working people.

An elderly person retires and suddenly has lots of free time. This step, in most cases, is very sudden and takes place without adequate preparation. The resulting leisure time can be experienced as a liberation or as a punishment. Technology, in this context, takes effect in dissociation from the technical working environment. It is the elderly people's free decision whether they continue to identify themselves with this world or not. Distance results in freedom and this freedom can be a benefit in higher age, if you know how to handle it.

It addition, it can be mentioned that in former times, technology has supplemented nature, for example, by using a tool to carry out an activity more easily. Now, technology is not only a means, but also the purpose of things; hence it replaces nature. Thus, technology becomes an end in itself [9]. And finally, we could regard technology almost as a religion. Humankind has always referred to the fact that a religion conveys a long-term promise of salvation to be fulfilled after death. Technology, on the contrary, does not call for a longterm perspective, it fulfills this promise of salvation right away.

\section{Empirical Study with Ambient Assisted Living}

The presented considerations were also studied in a project in Austria between 2014 and 2017. In total, twelve project partners worked on this joint project, including four research facilities, two ICT providers as well as six mobile and social service providers. It was the aim of the study to test modern technical service applications in 70 households with elderly people.

The project emphasized on the individuality of the participants so that it was possible to test - depending on individual wishes and needs - different technical solutions. They were summarized under the termsmart homes and smart services and included, for example, home automation systems like automatic lightning control, communication solutions like video telephony via tablets, security solutions like an automatic fall detector or entertainment solutions like games for tablets.

The aim of the project was to test systems which were available on the market or were at least marketable. So, at the beginning of the project, providers of AAL solutions in Europe were contacted in order to place their products in a product catalogue. Approximately 80 providers were found; their solutions were grouped in categories and matched with the individual needs of the participants, which had been identified in a qualitative survey. Thus, individual solution packages could be prepared for the participants that were bought, installed and tested over an evaluation period of one year.

During the evaluation period, the participating scientists were especially interested in the fact which technical systems and applications really supported elderly people and which were accepted by them. For this reason, they developed an evaluation strategy which consisted of qualitative and quantitative elements. In the framework of this mixed-methods approach [10], several surveys took place. At the beginning and at the end of the test period, the participants were asked for their attitudes towards and experiences with technical devices by means of a quantitative questionnaire. Furthermore, at eight-week intervals at five points of time, so-called regular questionnaire surveys were conducted, where participants were asked for their emotions and the effects of the technical solutions on certain areas of life (daily activities or everyday rhythm, mobility, convenience, independence/ dependence, health, individual feeling of safety as well as contact frequency with family or friends). In addition, in order to collect qualitative data, meetings were organized, where participants could talk about their experiences and reflected on the use of the solutions.

It turned out that for elderly people, in particular, the topics communication and safety were of key importance. So, video telephony via Skype on a tablet was widely accepted and used as it creates considerable additional value for the participants. Especially if relatives live farther away, this is a useful and easy-touse means to stay in contact, not only via telephone, but also with a moving picture. Elderly people also gladly accepted the possibility to have pictures uploaded into an album on their tablet from an 
external device, as these pictures connect them with their family and current events can be communicated visually as well. The participants identified communication as a key aspect that can be improved through technical support.

The participants also valued the different solutions for fall detection. Here, sensors were used which could reliably detect falls in the home environment and raise an alarm to a stored contact, but also mobile systems which allow GPS tracking outside of the apartment. It became evident that the mere presence of these solutions led to an increased feeling of safety in elderly people, they felt more comfortable in their own surroundings. One key finding is that the systems must work reliably in order to be accepted by elderly people. If an application works unstably or causes a false alarm, its functioning will be questioned and its use rather declines.

Usage also depends on the fact to what extent elderly people are encouraged to use technology. Due to a socialization process with little or no technology at all, the benefit is not always obvious and the devices are rarely used. However, this improves if close persons, relatives or employees of care facilities offer assistance or suggest the use. There is a willingness to adopt new technologies in the majority of participants provided that they can see the respective personal benefit.

However, we need to be critical of the fact that most of the participants used the technical solutions only because they were offered free of charge within the framework of the project. In most cases, purchasing the devices themselves would be out of the question as the cost-benefit-ratio seems inconclusive. It is also still unknown who is the actual target group for the AAL solutions. Based on the project experience we can say that in most cases the relatives are the ones who purchase the devices and not the elderly people themselves.

\section{Synthesis}

Technology presets behavior, technology makes man its slave. There is no choice (example: radio keys for cars). Man is seen as consuming machine who has to follow the rules. Compatibility for elderly people is primarily driven by this consumerism.

It would be desirable if technology could satisfy individual wishes and needs. Given the subjectivity of people, this is going to be difficult. Individuality in the design of products was lost by the introduction of mass production. Only the configuration options offer a chance for individualization. Today's society is very individualized, where as mass production prevents or even destroys individualization. This means that individuality is available only to a privileged stratum of society that is able to afford it.

Technology can only satisfy the needs of elderly people if it pays off; that is, for economic reasons. For the producers of technical devices this means that they have to attract elderly people's interest for consumption and to convince them that technical devices can be useful for them in different categories. Various difficulties were presented. For example, that in the field of networking and digital communication, technology must be much more convincing as elderly people are not able to fully familiarize themselves with it in the long-term.

From the point of view of elderly people, also today's throwaway-society is an argument against mechanization. For elderly people it is much more difficult to accept a technical world that is not interested in repairing things, but supports their replacement or new purchase. Unlike younger people, especially elderly people often insist on an attempt to repair things and to use them for as long as possible.

There is enormous potential in the area of mobility. A lots till needs to be improved, a lot still needs to be moved. An obstacle on this way could be described as follows: there exists a contradictory image, namely that elderly people are fit and healthy. This implies that elderly people - who do not match this image - rather with draw in order to not be caught in this contradiction.

In relation to games, it needs to be said that they have no real reference to elderly people's living environment due to being virtual and intangible. The question is whether there is a possibility to overcome this obstacle? This means, an answer to the question how to put virtual reality in direct relation to real life.

We can see that technology in all areas strongly influences the living environment of elderly people as a powerful subject. It is based on a power structure. Technology sets high demands; on the one hand, the demand to replace nature as the work of human beings, and, on the other hand, to govern the living environment of man. Technology's promise of salvation only has a temporary effect; development goes on and on, there is progress. Salvation, in this context, means a feeling of happiness, which, however, only has little resonance in elderly people. A possible reason for this might be the aspect of mortality. Elderly people see little benefit in short-term moments of happiness, they prefer a more long-term perspective. For them - in view of their own mortality -moments of happiness based on technical devices are irrelevant.

And, eventually, there is the aspect of being part of it, not only physically but mentally, too. 'Mental mobility' can be sidestepped by using up-to-date technological devices which offer lots of possibilities for compensation. On the other hand, people who do not keep up with progress age faster. We live in a society that promotes a rather negative image of old age. Technical support possibilities offer a chance to change this image and to make it more positive in many aspects. This is a new challenge when dealing with elderly people. It is about their ability to adapt.

The question of age also includes the question about the meaning of old age. Luhmann [11] deals with the question of meaning in his main work Soziale Systeme. The phenomenon meaning is a form of surplus of references to further possibilities of experiencing and acting. Something's are in focus, in the center of intention, and other things are mentioned just incidentally as a horizon take-up experiencing and acting. Everything that is intended 
keeps all options open and, thus, also guarantees up-to-datedness in new accesses. Therefore, the construction of meaning is indeed an individual process, but meaning can only be stabilized through further possibilities to experience and act, i.e. in contact with nature and society. That is, if I, as an individual, young or old, do not have the possibility to experience and act, then life, for me, loses its meaning. The possibilities, however, arise through communication as the human being is a social creature [12]. The loss of community and the subsequent isolation of the individual entail termination of communication and loss of meaning. As an individual, I am able to find a meaning in my life without communication, but this meaning can only be developed through alignment with another meaning, e.g. through communication. By means of such a development, the meaning can be stabilized and can further unfold. Thus, meaning is basically unstable, reality can only have a meaning if the systems within can further develop.

Communication is sort of a producer and stabilizer of meaning In this context, the meaning of old age is the communication with society. But the question is what should be communicated? Age has the obligation to make up the balance of all life experiences, to review all memories of the last six to eight decades and to let them be present in the presence. This means that the meaning of old age lies in bilateral communication - the elderly talk about their experiences and society listens and debates. We increasingly witness that the inclination to talk and to listen decreases in our modern digital world. Empirical results show that communication is very important to people in higher age. Only then, they can enjoy a feeling of well-being. It is not enough to keep elderly people physically fit. Taking work as an example we can see that a raising of the retirement age offers people the possibility for communication and self-awareness in society until the age of 67 . Seen from that perspective, this sounds positive.

Technical progress, however, points in another direction: the elderly shall find their way to independence in the already discussed subcategories. This is what Ortega Y Gasset [13] already predicted in his work on technology in the 1940s.,,Technology is the opposite of the adaptation of the subject to the means, because it is the adaptation of the means to the subject. Animals adapt to the means, but man adapts the means according to his wishes. Thus, something supernatural arises which we call technology. Today, we experience nature through technology. From a scientific viewpoint, this means of perception resulted in rapid progress and in-depth knowledge of nature. It is possible to register extremely tiny particles at the microscopic level and new galaxies at the macroscopic level Technology, as we already know, also functions as subject, whose object of investigations man. Our perception was changed in such a way that we consume what is offered. According to Ortega Y Gasset [13], technology is by no means restricted to the mere satisfaction of necessities that lead to a good life.

Technology provides an easy-to-use smartphone for elderly people and a simple software for communication within the network, but the content of the communication is shortened and structured in such a way - by means of SMS, Twitter or Facebook, etc. -that many elderly people are unable to use it. They have no option but to visit virtual graveyards. The term good life is no longer related to meaning, but to the reduction of effort. According to Ortega Y Gasset [13], the mere well being in the world allows the emergence of the superfluous. Even the things which are objectively necessary for man are only necessary in view of the superfluous". Therefore, the most important for technology is the production of the superfluous. Today, we experience this in all categories of technology: more means of communication, more convenience, more mobility, etc. right up to the limits of the superfluous. According to Ortega Y Gasset [13] technology is the effort to save effort or in other words, It is what we do to completely or partially avoid activities which are mainly forced on us by nature.

Where does this saved effort take us and what remains? Once man, due to the technical activity, will be free from all efforts that nature has forced on him, what will he do, which activities will fulfil his life? This is the very question which is in the foreground in context with technology and age. Many old people lose their zest for life and well-being precisely due to more communication or convenience which, in reality, should lead to more independence, and hence face a crisis of meaning.

\section{References}

1. WHO (2002) Proposed working definition of an older person in Africa for the MDS Project.

2. Wang QE, Myers MD, Sundaram D (2013) Digital Natives and Digital Immigrants. Business \& Information Systems Engineering 5(6): 409419.

3. BMBF Federal Ministry of Education and Research (2008) AAL Ageappropriate assistance systems for a healthy and independent life, ambient assisted living. Federal Ministry of Education and Research, Berlin, Germany.

4. Jonas H (1985) Technology, medicine and ethics. On the practice of the principle of responsibility. Frankfurt, Germany.

5. tAALxonomy (2015) tAALxonomy-Development of a workable taxonomy for the effective classification of AAL products and services.

6. Hubig C (1993) Technology and science ethics A guide. Springer, 1 Berlin, Germany.

7. Cassirer E (1995) Form und Technik. In: Cassirer E, Werle JM, Orth EW, Krois JM (Eds.), Symbol, 1927-1933. My Felix Verlag GmbH SS, Hamburg, Germany, pp. 39-91.

8. Brinkmann D (1946) Man and technology: fundamentals of a philosophy of technology. A Francke Verlag, Germany.

9. Anders G (1980) The antiquity of man, München, Germany.

10. Mayring P (2001) Kombination und Integration qualitativer und quantitativer Analyse. Forum Qualitative Sozialforschung. Forum Qualitative Social Research 2(1): 6.

11. Luhmann N (1984) Social systems. Outline of a general theory. Suhrkamp, Frankfurt, Germany.

12. Göckenjan G (2000) Das Alter würdigen. Frankfurt, Germany.

13. Ortega Y Gasset J (1949) The considerations about the technique. German publishing house, Stuttgart, Germany. 
(c) (P) Creative Commons Attribution 4.0

For possible submissions Click Here

Submit Article

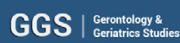
Benefits of Publishing with us

- High-level peer review and editorial services

- Freely accessible online immediately upon publication

- Authors retain the copyright to their work

- Licensing it under a Creative Commons license

- Visibility through different online platforms 